\title{
Reseña de Monsálvez Araneda, Danny, Los bandos militares en Concepción y Talcahuano: Disciplina militar y disciplinamiento social, Concepción (Chile), Escaparate, 2014, 271 págs.
}

\author{
YERKO A. ARAVENA CONSTANZO \\ Licenciado en Historia, Universidad de Concepción, Chile \\ yerkoaravena@udec.cl
}

El libro Los bandos militares en Concepción y Talcabuano: Disciplina militar y disciplinamiento social del historiador Danny Monsálvez Araneda, resulta ser un aporte significativo, considerando la poca presencia de trabajos que rescaten la historia y la memoria en torno a la violencia política y la violación a los Derechos Humanos desde una perspectiva local, en donde existe un gran vacío al respecto aún cuando la región del Biobío, octava región de Chile -lugar geográfico al cual esta investigación se circunscribe- fue fuertemente golpeada por la dictadura cívico-militar. Ha existido una constante en la historiografía chilena que tiende a centrar su atención en lo "nacional", lo que en la práctica se sujeta a una visión general o bien en una mirada reducida de lo acaecido ceñida siempre al quehacer en las grandes ciudades, como si las demás comunidades no tuviesen historia o como si su historia dependiera irrestrictamente de estos grandes centros urbanos. Sin duda esto resulta ser una gran deuda de quienes nos desempeñamos en la disciplina histórica, ante lo cual esfuerzos como éstos dan cuenta de un interesante giro historiográfico. Este trabajo posee la virtud de romper con aquella visión; si bien parte de una mirada global a nivel nacional, es capaz de situarlo en un contexto local, matizarlo con este espacio, y mostrar sus particularidades.

Por otro lado, es un aporte en la medida que también es un trabajo dirigido a poner a nuestra disposición fuentes de la época, algo fundamental si queremos establecer una investigación de este tipo. El estudio de los bandos militares que aborda el autor nos muestra, a través de estos, las diversas acciones que tomó la dictadura para su instauración y consolidación desde un punto de vista jurídico-institucional, dándose a sí misma un sustento legal que le daría contenido y coherencia a cada una de sus acciones. En efecto, los bandos militares poseían la cualidad de ser diversos en su contenido y amplios en su alcance, por tanto abarcaban diversos ámbitos de la sociedad, organización civil y política, dejando en evidencia el nivel de intervención al que se aspiraba -claramente absoluto- y la forma con la que se pretendía lograrlo, legitimando el uso de la violencia política y el terrorismo de Estado, interviniendo los campos de acción de los enemigos declarados por la Junta Militar y estableciendo la legalización del terror.

En palabras del autor, este trabajo:

“[...] tiene como objetivo dar una mirada general y de conjunto a determinadas modalidades y diseños que adquirió la violencia y control social producto del golpe de Estado de 1973; es decir, identificar algunos dispositivos legales y punitivos a través de las cuales se expresó la violencia política y el control social los días posteriores al 11 de septiembre de 1973" (pág. 13).

Así pues, nos proporciona la materia prima para adentrarnos en la temática más allá de la ya típica exhibición de los hechos de la coerción; este material de consulta nos muestra una mirada resumida, pero a su vez amplia y resulta ser un excelente punto de partida para quienes quieran adentrarse en materias de violencia política y cómo la violencia emanada desde el Estado afectó a nuestros territorios a través de diferentes medios de coacción. 
Para ello, se detiene en un punto que muchas veces ha sido pasado por alto: la construcción jurídico-institucional del régimen dictatorial a la par de la perpetración de la violencia más brutal por parte de éste previamente a la elaboración de la constitución política de 1980. Junto con esto, nos muestra cómo la dictadura justificó y legitimó cada una de sus acciones no sólo mediante el uso de la fuerza, también mediante el terror, la desinformación, la militarización del espacio público y el control de todos los espacios de asociatividad y representatividad popular.

Para lograr aquello, elabora su trabajo en 3 capítulos. En el primero de ellos, describe la coordinación de las ramas de las Fuerzas Armadas y de Orden locales para perpetrar la coerción a pobladores, trabajadores y estudiantes de la zona -principalmente a los que militaban en partidos de izquierda y/o adscribían al gobierno de la Unidad Popular- durante los primeros días posteriores al golpe de Estado y como los militares lograrían, en pocos días, el control de la zona. Según el autor:

"El 11 de septiembre de 1973, Concepción era visto como una 'zona roja', con una marcada presencia de los partidos, agrupaciones y movimientos de izquierda, tanto de aquellos que conformaban la Unidad Popular, como de quienes se situaban fuera de ella, es por ello, que la acción militar de aquel martes 11 tuvo como uno de sus principales objetivos el rápido control de Concepción y sus alrededores" (pág. 21).

A través de este planteamiento, nos muestra el nivel de planificación y preparación de los diversos operativos que dejarían el país en las manos castrenses poco después de transcurrido el asalto al palacio de La Moneda. Allanamientos, intervención de las líneas telefónicas de las organizaciones de izquierda, encarcelamientos masivos, control de los medios de comunicación de masas, invasión del espacio público, etcétera, acompañarían a las torturas y asesinatos, todo efectuado sincronizadamente y ejecutado de forma paralela, dejando a la luz el carácter mismo de una dictadura que no daría tregua.

Por diversas razones -ya sea por el impacto de las violaciones a los derechos humanos en la sociedad o bien por la manipulación de los hechos históricos por los gobiernos de turno- se ha centrado el análisis de este período en la violencia política más visible, lo que resulta ser la represión, tortura, desaparición y asesinatos de personas en nuestro país. Si bien esto es innegable y, por su magnitud, ha sido difundida y masificada por los medios de comunicación hasta el día de hoy, no podemos obviar que la violencia no actúa por si sola ni para sí misma; es un instrumento de un grupo para someter a otro, por un lado, y esta va más allá de lo coercitivo, necesita elementos de legitimación de su uso en la sociedad.

Por lo mismo, los capítulos 2 y 3 de este libro nos entregan un insumo importante para rescatar. Es en estos capítulos donde se abordan los aspectos relevantes del marco jurídico-institucional transitorio antes mencionado que usaría la dictadura chilena para poder operar tal y como lo hizo - en el capítulo 2 se analizan los bandos militares y los decretos ley, mientras que en el 3 se exhiben las transcripciones de todos aquellos que fueron dictados para Concepción y los departamentos de Talcahuano y Tomé-, además de plasmar los lineamientos fundamentales del cómo la dictadura interactuaría con el resto de la sociedad, tanto con sus adeptos como con sus detractores o enemigos declarados. Tal y como nos señala el historiador Danny Monsálvez:

"Si bien los bandos tuvieron - cronológicamente hablando - breve duración, su importancia no radica en aquel punto, sino, en su efectividad, ya sean en cuanto a mensaje a la población, como las medidas que éstos contemplaban. En aquel mes de septiembre de 1973, los bandos, desde el punto de vista factual pasaron de delimitar el campo de lo permitido y prohibido, así como lo legítimo e ilegítimo no sólo en el ámbito político, social también valórico y cultural” (pág. 37) 
Por lo mismo, no podemos hablar sobre la violencia y el control social de aquella época sin considerar aquel aspecto al cual el autor, con justa razón, da tanto énfasis.

Entonces, este libro nos da claridad sobre dos aspectos trascendentales: I) el uso de la violencia durante la dictadura, lejos de ser aplicada de forma arbitraria e irracional, fue de lo más racional y sistematizada, además de ser selectiva y controlada; por ende II) poseía objetivos claros y concretos y no era una improvisación ni mucho menos aspiraba a entregar el poder a los civiles sin antes salvaguardar los intereses de quienes pidieron a gritos la perpetración del golpe de Estado, por un lado, y se trataba de un giro radical del sistema con tal de que las experiencias populares de organización política y social no volviesen a ocurrir y que no reapareciesen para amenazar los intereses de la clase dominante, sacando así de escena a todo el activo político y bloqueando su posible reingreso a la escena pública nacional y local.

Entonces, el trabajo del profesor Monsálvez logra sintetizar la violencia política ejercida desde el Terrorismo de Estado emanado desde la dictadura cívico-militar. Es más, podemos ver que esa violencia es el componente principal no sólo de la dictadura misma, sino que también lo es del sistema que defendió y del modelo que instauró, el cual, dicho sea de paso, es el que nos gobierna hoy en día. Junto con esto, plasma esa relación entre el marco legal y el marco de acción de la dictadura, esa figuración en el papel que necesita todo grupo que atenta contra el pueblo para pasar a la legalidad su actuar ilegítimo.

Existe un consenso dentro de la historiografía sobre la época en cuanto a que la implantación del modelo neoliberal hubiese sido imposible de realizar sin el estallido de diversas dictaduras a lo largo de nuestro continente. Sin violencia, nuestro sistema actual no hubiese visto la luz ya que no se trataba de algunas reformas aisladas, sino de una transformación radical de lo existente para perpetuar los beneficios de los poderosos, de desarticular a los trabajadores y trabajadoras y de replegar a la población a un papel ya no sólo pasivo, sino más bien inexistente, siendo estos últimos aspectos -mencionados por diversos autores- fundamentales para la implantación del modelo neoliberal. En otras palabras, todo esto fue necesario para dejarle libre el camino al mercado y la tarea fácil a quienes posteriormente les tocaría salvaguardarlo e incluso profundizarlo.

Por último, pero no menos importante, este libro nos advierte sobre la necesidad -para la clase dominante- de la implantación de la dictadura. La política represiva institucionalizada en general y la acción del despliegue militar del 11 de septiembre de 1973 en particular, poseía como principal objetivo un rápido y efectivo control sobre la población de la región, principalmente en los sectores más politizados y combativos de ésta y, aunque no existió una real resistencia a la dictadura por la dimensión de la misma, la represión hacia estos sectores fue implacable, creándose una guerra inexistente en donde sólo había un bando el cual saldría victorioso a sangre y fuego. Esto cumpliría una doble función: I) desarticular a la oposición, a la dictadura, a la izquierda en su conjunto y a cualquier foco de resistencia y II) evitar cualquier rearticulación de la izquierda y borrar la influencia que ésta tuvo por tantas décadas en el pueblo chileno. Más allá de eso, el objetivo de aquello fue desarticular socialmente a nuestro país, fragmentarlo y evitar cualquier posible reaparición en escena de alguna expresión de organización popular y, de existir ésta, que sólo se desarrollase bajo los lineamientos institucionales impuestos o bajo los dictámenes que el modelo señalase, siempre buscando perfeccionarlo, pero sin ir más allá de éste.

Hoy en Chile vivimos en un clima de impunidad, en donde los crímenes perpetrados en este oscuro período de nuestra historia siguen aún remeciendo una sociedad que, después de cuarenta años, sigue escarbando en su memoria buscando respuestas en la historia de los problemas que aquejan a la sociedad neoliberal chilena. Es por eso que este trabajo posee un valor agregado sin querer tenerlo, puesto que su misión -aunque nos hubiese gustado que fuese de forma explícitano apuntaba precisamente a aquello. Asimismo, hace frente a una historiografía que aún no se ha 
hecho cargo -pese a que en los últimos años han aparecido varios trabajos sobre el tema- de los hechos de violencia que han marcado nuestra historia reciente, a diferencia de otros países, como Argentina y España, en donde se han desarrollado interesantes líneas investigativas al respecto.

Para finalizar cabría realizar algunas observaciones fundamentales. El disciplinamiento social de nuestra sociedad se obtuvo mediante la muerte y desaparición de personas, se detuvieron así el avance del movimiento obrero y popular y la construcción de alternativas a la sociedad de la época a través de la violencia para así instaurar el modelo que hoy nos rige, hecho acaecido a la largo y ancho de nuestro continente en un contexto que, si bien es parte del pasado, está aún vigente en nuestro presente histórico. De esta forma, lo antes planteado toma plena vigencia si vemos la reactivación de los movimientos sociales y la aparición de nuevos conflictos en diversas partes del mundo producto de las crisis y contradicciones del sistema capitalista. Por ende, no todo está dicho ni resuelto. Libros como éste nos recuerdan aquello y nos plantea un interesante punto de partida para ver dónde se origina toda esta violencia y barbarie que vemos cada día en diferentes rincones del orbe. ¿Dónde se origina la violencia? Si leemos las páginas de este libro, nos quedará claro quiénes son los gestores de dicha violencia; proviene de aquellos que a través de la historia han golpeado a nuestros pueblos para detener el curso de la misma. 